Vol. 6, No. 2, 2020

\author{
Ihor Zhuravel $^{1}$, Lesia Mychuda ${ }^{2}$, Yurii Zhuravel ${ }^{3}$ \\ ${ }^{1}$ Department of Information Technology Security, Lviv Polytechnic National University, Ukraine, Lviv, \\ S. Bandery Street 12, E-mail: izhuravel@ukr.net, ORCID 0000-0003-1114-0124 \\ ${ }^{2}$ Department of Information Technology Security, Lviv Polytechnic National University, Ukraine, Lviv, \\ S. Bandery Street 12, E-mail: lesia.z.mychuda@lpnu.ua, ORCID 0000-0001-8266-1782 \\ ${ }^{3}$ Department of Information Technology Security, Lviv Polytechnic National University, Ukraine, Lviv, \\ S. Bandery Street 12, E-mail: yura_zhur@ukr.net
}

\title{
LOCALIZATION OF STEEL FRACTURES BASED ON THE FRACTAL MODEL OF THEIR METALLOGRAPHIC IMAGES
}

Received: August 14, 2020 / Revised: September 29, 2020 / Accepted: September 30, 2020

(C) Zhuravel I., Mychuda L., Zhuravel Y., 2020

\begin{abstract}
There are a number of tasks that require assessment of the condition of the material and its mechanical characteristics. Such tasks may arise at the production stage, when there's a need to control the content of various components of the material, strength, hardness, etc. Also similar tasks arise during exploitation of materials, which is especially relevant today, when most of the responsible products and structures in the field of nuclear energy, chemical industry, machinebuilding industry are on the verge of wearing down. Previously defectoscopy methods were mainly used to assess the reliability of such materials and products. These methods provided information on the presence or absence of a defect. But to prevent accidents, information about the pre-defective state of the material itself and the degree of its degradation is needed. Approaches involving methods and means of solid state physics, mechanics, chemistry, materials science and other scientific disciplines have become more informative for describing the state of degradation. However, these methods are quite laboursome and time consuming and cannot be applied to transient processes. Therefore, it is important to develop a method that would be based on the analysis of the microstructure of the material would allow to obtain its numerical mechanical characteristics. This approach would be used at the production stage of materials to determine their components and mechanical characteristics and at the stage of exploitation to determine the degree of degradation of the material. It is known that the fractal dimension of each microstructure of the material is an indicator of its qualitative characteristics. Thus, the numerical value of the fractal dimension establishes the relationship between the structure and the mechanical properties of the material. In this work the method of localization of fractures of heat-resistant steels on the basis of fractal models of metallographic images is developed and its advantages in comparison with other known approaches are analyzed.
\end{abstract}

Keywords: metallography, physical and mechanical properties of the material, brittle and viscous fracture, level of material degradation, fractal dimension.

\section{Introduction}

In the construction of bridges, pipelines and gas pipelines, in mechanical engineering and other similar structures metal, in particular, various steels, is used most often. During exploitation, over time and under the influence of external factors, the metal loses its original mechanical properties, degrades and collapses. The main types of failure are viscous or plastic and brittle [1]-[3], which depend on the exploitation conditions. For example, steel at a temperature of about 200 for the case of simple forces (stretching, compression, bending) has less resistance to shear than separation, so it collapses plastically. At the same external actions, but at low temperatures, there is a brittle destruction [4], [5]. 


\section{Localization of Steel Fractures Based on the Fractal Model of Their Metallographic Images}

Therefore, knowing the type of metal destruction, you can simulate the reasons that led to it. This makes it a relevant task of automatically identifying areas with different types of destruction, which will eliminate the influence of the human factor and increase the accuracy of the analysis.

To describe the textures of images with different types of destruction, which are also called metallographic, two approaches are mostly used - statistical and textural [1], [6]. Among the main difficulties in studying and describing textures is that it is difficult to develop a universal method for their recognition. In other words, it is always possible to develop a method of recognizing any particular texture, which will be characterized by high efficiency, but will not be suitable for recognizing another type of texture. One of the reasons is that Euclidean geometry is mostly used in the development of methods for recognizing complex textures. It can characterize symmetrical structures that are not very common in metallographic images.

Research has shown that metallographic images are characterized by different values of fractal dimensions [1]. In works [7], [8] it is shown that the fractal dimension of each microstructure of the material is an indicator of its qualitative characteristics. Thus, the numerical value of the fractal dimension establishes the relationship between the structure and the mechanical properties of the material.

There are various methods for calculating the fractal dimension. The most commonly used are cellular and point methods [9]. These methods are based on estimating the area of a fractal figure at different values of the measurement step, and they differ only in the method of calculating this estimate. For example, the point method of calculating the fractal dimension takes the initial sampling of the input image as matrix of cells (pixels of the image). Next calculate the probability $P(m, L)$ of hitting the cell with the side $L$ (in pixels), in the center of which is a cell belonging to the fractal figure, for $m=1: L^{2}$. Calculation of the area of a fractal figure is determined by the formula:

$$
\langle N(L)\rangle \geq M \sum_{m=1}^{L^{2}} \frac{P(m, L)}{m},
$$

where $M$ - the total number of cells belonging to the fractal figure. Further calculations of the fractal dimension are performed according to the general scheme for all methods, which is described above [9].

The closest to the described method is the cellular one. According to this method, grids with square cells with different values of the grid step, which depends on the measurement step, are superimposed on the input image of the fractal, and the number of cells covering this fractal figure for each measurement step is calculated. Next determine the fractal dimension of the image as the tangent of the angle of inclination of a line, which is obtained by approximating the formed set of points by the method of least squares [9].

It has been experimentally established that the fractal dimension is a quantitative characteristic of the structure of any material [8]. Therefore, the apparatus of fractal geometry should be used to quantify the fractal microstructure, because the fractal dimension of each microstructure correlates with its qualitative characteristics. Thus, there is a relationship between the fractal dimension of the microstructure of the metal and its characteristics, in particular, physical and mechanical properties, which makes it possible to determine the qualitative characteristics of the metal based on the analysis of the fractal dimension of its microstructure [8]. The advantage of using the fractal dimension is its invariance in some types of affine transformations. This property makes it possible to analyze images of one scene, which are formed under different lighting conditions, with different scaling factors and different angles of rotation.

The correct calculation of fractal dimensions of images, including metallographic ones, takes into account several important aspects. Examine some of them in more detail. Optical metallographic images are halftone, and most methods of calculating fractal dimensions work only with binary images. Two ways are proposed to solve this task. The first method is to apply the optimal, in terms of detail, binarization threshold to convert a halftone image into binary [10], the second is to develop a method that would calculate fractal dimensions based on a halftone image without converting it into a binary representation [11]. The second aspect was that when calculating the field of fractal dimensions and fractal dimension of the whole image, it is important to choose the right size settings of the local aperture and the step of their change. In particular, in the case of constructing a field of fractal dimensions, the size of the local aperture should be commensurate with the size of the objects of interest in the image [12]. 


\section{Ihor Zhuravel, Łesia Mychuda, Yurii Zhuravel}

\section{Problem Statement}

Fractal dimension is only one number - an integral estimate, which cannot always provide a comprehensive characteristic of the image of a complex texture [11]. Quite often the numerical values of fractal dimensions of images with different types of destruction are very close, which can lead to errors in recognizing the type of destruction.

Therefore, to evaluate and recognize such complex textures, it is proposed to use multifractal methods [13]. Their involvement in solving this task is one of the promising and at the same time insufficiently developed areas, which opens up prospects for linking the parameters of quantitative analysis of the microstructure of materials with their physical and mechanical properties.

\section{Review of Modern Information Sources on the Subject of the Paper}

One of the tasks of the study of complex structured images is the statistical analysis of these objects - their number, area, shape, etc. Before performing such an analysis, these objects must be localized in the image. Various approaches are used to solve the task of localization of objects in the image. The most commonly used segmentation methods in technical diagnostic tasks include threshold methods [14], watershed methods [15], using a description based on a graph [18], textural methods and border selection [16], etc. These methods continue to be relevant for solving problems of technical vision, because the quality of image analysis as a whole depends on the accuracy of all objects, the accuracy of the localization of their shape. There are many approaches to image segmentation [15]-[18]. The choice of a method depends on many factors, such as the image itself, the complexity of the shape of the object under study, the task in question, and so on.

In general, all segmentation methods are reduced to dividing the image into sections, the pixels of which are united by some feature. In this regard, the structure of most segmentation methods is similar to the methods of texture classification [19]. It consists of two main steps - the selection of features to characterize the local neighborhoods of the image and the classification of these neighborhoods. Signs of individual pixels or local neighborhoods can be intensity values, statistical characteristics, adjacency matrix characteristics, and so on. The accuracy of the characteristics of the local neighborhood, on the basis of which the selection of objects will take place, depends on the choice of features.

Threshold segmentation methods are the easiest to implement. The accuracy of segmentation depends on the choice of the optimal threshold, which in the case of recognition can only be done experimentally. Another significant disadvantage of these approaches is that they do not operate correctly when processing images with uneven lighting and presence of noise.

\section{Main Material Presentation}

As noted above, images in non-destructive testing are usually characterized by a complex structure. This leads to the fact that different areas of such images will have different fractal dimensions. Until now, both global and local fractal dimensions have been used in the analysis of such images. The choice of the type of fractal dimension - global or local - largely depends on the task and the studied images. The global fractal dimension gives an integrated average estimate of the whole image. This approach can be used in the analysis of images with more or less the same image field structure. If the task is to select certain areas in the image and their analysis, then it is advisable to use local fractal dimensions, i.e. to build a field of fractal dimensions. When constructing a field of fractal dimensions, the cellular and point methods can be used [8], [9] or the method using the surface integral [11].

Examine the developed method of localization of objects in the image, which is solved using the field of fractal dimensions of the studied image.

As mentioned above, non-destructive testing images, in particular metallographic and fractographic, in most cases refer to images with a complex structure. The elements of this structure are characterized by different values of fractal dimensions. As a result, after constructing a field of fractal dimensions, a multimodal distribution is obtained. Each mode of such an image corresponds to a specific fractal object or texture and can be used to localize them. 


\section{Localization of Steel Fractures Based on the Fractal Model of Their Metallographic Images}

Examine the image of the fracture of steel 15Kh1MF on the weld (Fig. 1), operated for 190 thousand hours on the steam line of thermal power plants. Here against the background of viscous destruction, brittle fracture elements appear - they are highlighted in pic. 1. These elements appear due to the act of the working environment on the metal at high temperatures. Strength, and especially plasticity, is reduced. These elements are of interest to material scientists, so they need to be localized and their metric characteristics analyzed.

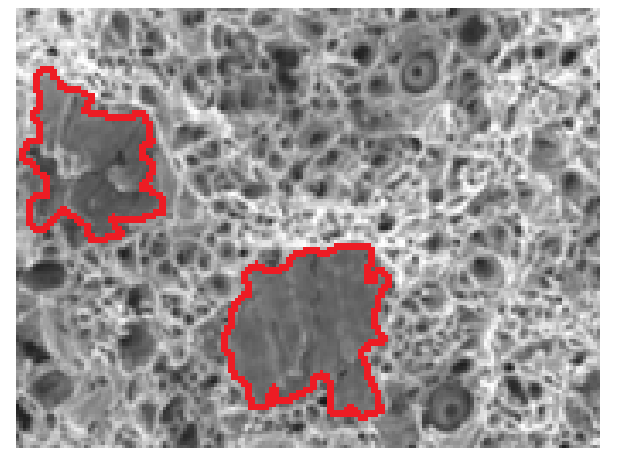

Fig. 1. The model of machine units of flat grinding machine

From the point of view of image processing, the data in Fig. 1 contain two types of structures. Obviously, they will be characterized by different values of fractal dimensions. Construct a field of fractal dimensions for the image in Fig. 1. In order to identify the best approach for constructing a field of fractal dimensions, two methods are used (Fig. 2): the known method of polygons [20] and our developed method of calculating the fractal dimension based on the surface integral [11]. It is known that the size of the local aperture significantly affects the efficiency of the analysis [12]. It should be as small as possible to provide detail and be commensurate with the objects of interest to ensure their localization. For our case, the size of the local aperture in the range from 10 to 20 will be acceptable.

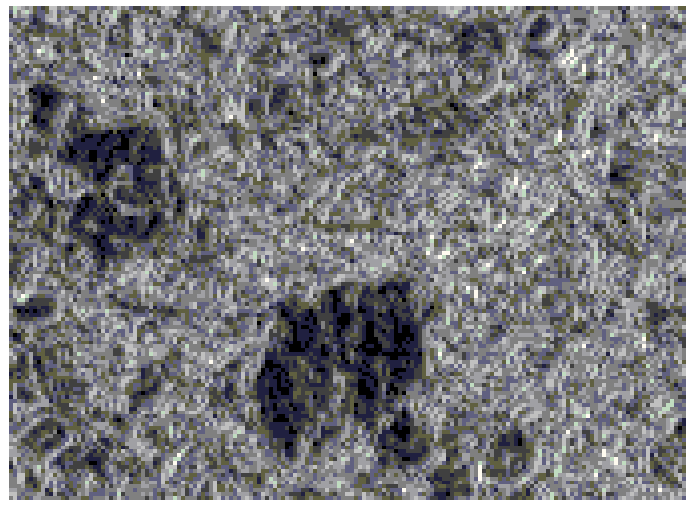

a

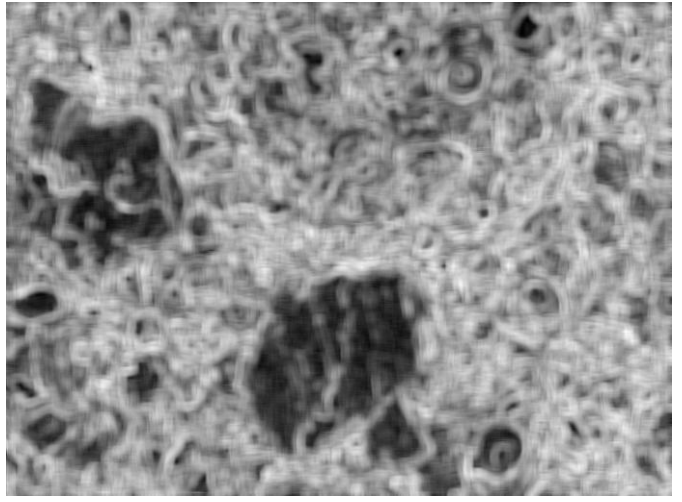

$\mathrm{c}$

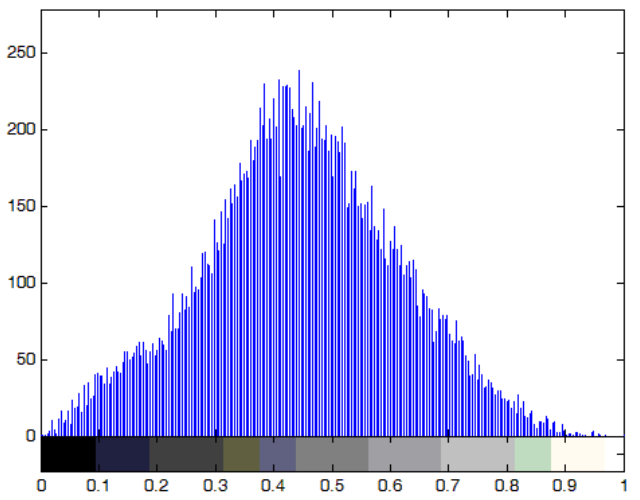

$\mathrm{b}$

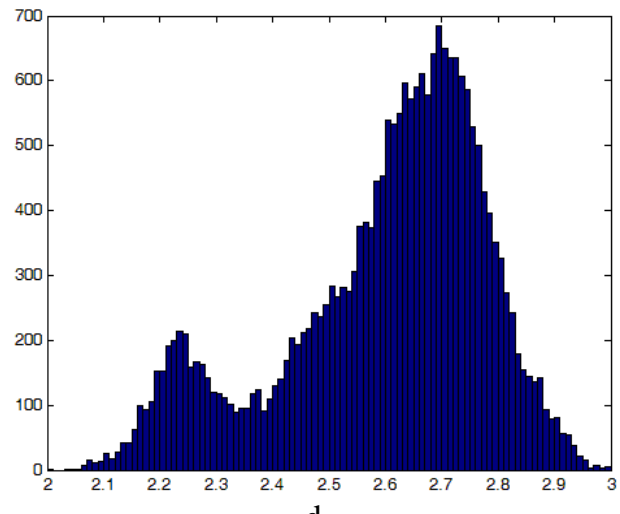

Fig. 2. A field of fractal dimensions calculated using the known method of polygons (a) and the method using the surface integral (b) and the corresponding histograms (c) and (d) 
Figs. $2 a$ and $c$ show the results of calculating the field of fractal dimensions using the known method of polygons [20] and our developed method of calculating fractal dimensions using the surface integral [11], respectively. In Figs. $2 a$ and $c$ the results are demonstrated of calculating the field of fractal dimensions using the known method of polygons [20] and our developed method of calculating fractal dimensions using the surface integral [11], respectively. In order to visualize the values of fractal dimensions were reduced to the range $[0,1]$. In Figs. $2 b$ and $d$ the distribution of the calculated values of the field of fractal dimensions are demonstrated. Presented in Fig. $2 b$ histogram has two distinct modes. This indicates that the studied image (Fig. 1) has two main types of textures, which are characterized by ranges of dimensions $2,2 \pm \varepsilon$ and $2,65 \pm \varepsilon$. These values can be used as thresholds for binary selection of texture types (Fig. 3). The parameter $\varepsilon$ determines the width of the range of values of fractal dimensions that are specific to a certain type of texture or a certain area in the image. The parameter $\varepsilon$ also affects the accuracy of object localization and their metric characteristics. It is determined, for the most part, experimentally. Because the input images contain noise, various inclusions, to eliminate them may require additional morphological processing. The question of the influence of noise on the fractal dimension will be investigated later in this paper. Regarding the histogram in Fig. $2 b$, which is obtained using the known method of polygons, it is single-modal and does not contain clear information about the main types of textures in the image.
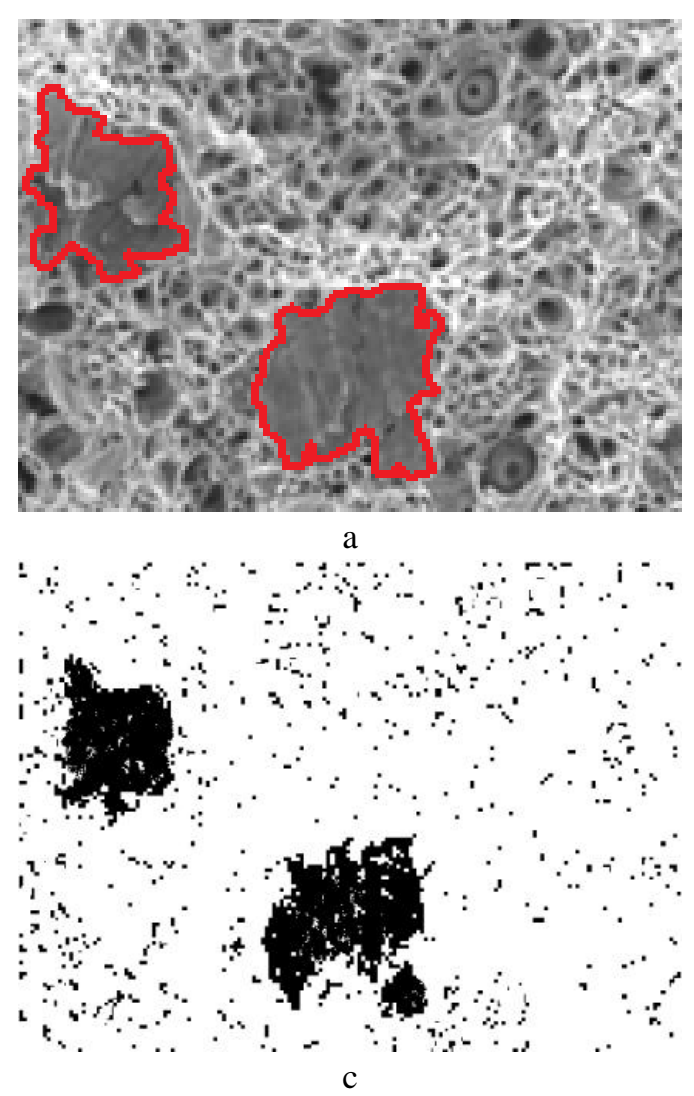

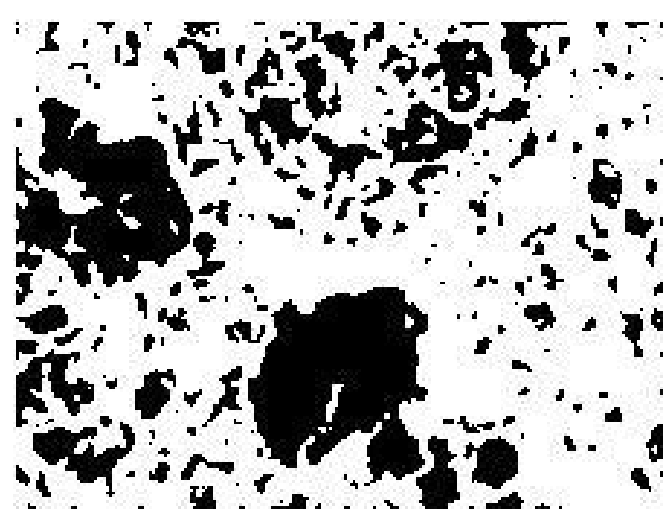

$\mathrm{b}$

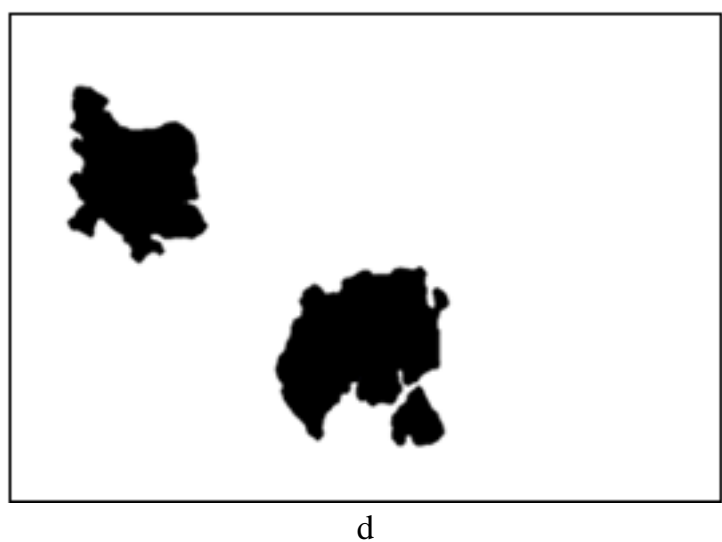

Fig. 3. Images of brittle fracture elements localized using the segmentation method with the optimal threshold (b) [10], the method of polygons (c) and the method using the surface integral (d)

Fig. $3 a$ presents a fractographic image with elements of brittle destruction, which are highlighted by material experts. In Fig. $3 b$ the result of localization of the object of interest using binarization with the optimal threshold are shown [10]. As suggested above, threshold methods cannot be effective in localizing different types of fractures, as they lead to the localization of faulty objects.

Figs. $3 c$ and $d$ represent images that are formed using the known method of polygons $(c)$ and the developed method of calculating fractal dimensions using the surface integral $(d)$. These images show the results of the localization of brittle fracture elements as black objects. A white background is a viscous 


\section{Localization of Steel Fractures Based on the Fractal Model of Their Metallographic Images}

destruction. The binary image in Fig. 3 in addition to the elements of brittle destruction also contains many other erroneously selected objects. The method of calculating the fractal dimension using the surface integral proposed in the work provided a more accurate selection of the elements of brittle destruction (Fig. 3 d). This advantage of the proposed method can be explained by the use of the surface integral, which, in contrast to the known method of polygons, takes into account all the differences in the intensities of the local neighborhood and allows to more accurately calculate its fractal dimension.

If the area of brittle destruction elements selected by material experts (Fig. $3 a$ ) is considered an etalon, the method using the surface integral provides $17 \%$ greater accuracy of localization of objects of interest compared to the known method of polygons. It should be noted that the accuracy of localization is sensitive to settings, in particular, the size of the local aperture and visual image quality.

In general, the results obtained in the study of methods of localization of areas of different types of destructions serve as a basis for material researchers to conduct various metric studies, calculate the percentage of viscous and brittle destructions, and so on.

\section{Influence of noise on fractal dimension of images}

The system of digital image formation is characterized by certain errors that are random and this is the cause of noise. The noise level is significantly affected by the size and type of matrix elements, their distortion, matrix sensitivity, exposure time, and so on.

In general, there are two main types of noise - intensity noise and chromatic noise. In the first case there are distortions of levels of intensities, in the second - colors. Noise distorts the visual perception of the image. It is especially noticeable in areas of low-intensity images. Many methods of noise cancellation are known. This is due to the existence of a large number of image classes and the nature of the effect of noise on the image - additive, multiplicative, pulsed, and so on.

Let us investigate the influence of different types and levels of image noise on the calculation of their fractal dimension [12]. When calculating the fractal dimension of the image the best convergence of cellular and point methods will be used [8], [9].

To estimate the level of image distortion by different types of noise, the ratio of the peak signal level to PSNR noise is used, which is calculated by the following expressions

$$
P S N R=10 \cdot \lg \left(\frac{R^{2}}{\frac{1}{N \cdot M} \sum_{i=1}^{N} \sum_{j=1}^{M}\left(L(i, j)-L_{\text {noise }}(i, j)\right)^{2}}\right),
$$

where $L(i, j)$ and $L_{\text {noise }}(i, j)$ - elements of the input and noisy image, the dimensions of which are equal $N \times M ; R$-image intensity range (for eight-bit $R=256$ ).

One of the most common types of noise is Gaussian noise. It is characterized by a normal distribution (3) and an additive way of influencing the image readout.

$$
u(t, x, y)_{\mid x=0}=u(t, x, y)_{\mid x=l}=0 .
$$

where $\mu$-mathematical expectation; $\sigma^{2}$ - variance of a random variable.

When forming test images with Gaussian noise, a mathematical expectation is assumed $\mu=0$, and let the variance $\sigma^{2}$ be equal to $0.01,0.05,0.10$ and 0.15 for the case when the value of the intensity of the eight-bit image will occupy the entire possible range [0, 255] (Fig. 4).

In Fig. 4 the values of fractal dimensions for the same test image are shown, but with different Gaussian noise levels. They vary from 1.9574 to 2.0259 when changing the variance of the noise component $\sigma^{2}$ from 0.01 to 0.15 . Based on the obtained results, it can be concluded that the above Gaussian noise has only a negligible effect on the calculation of fractal dimensions, since the maximum deviation from the fractal dimension of the input image is $2.5 \%$. 


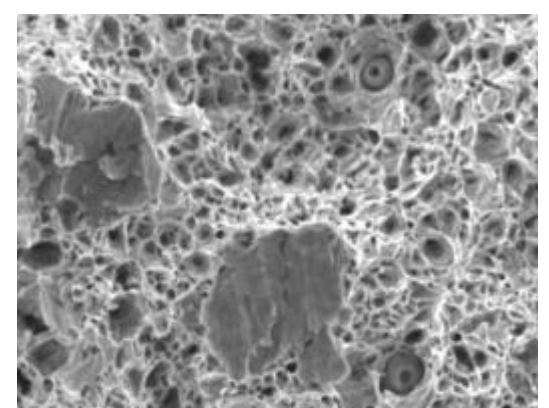

a) Input image fr $=1.9574$

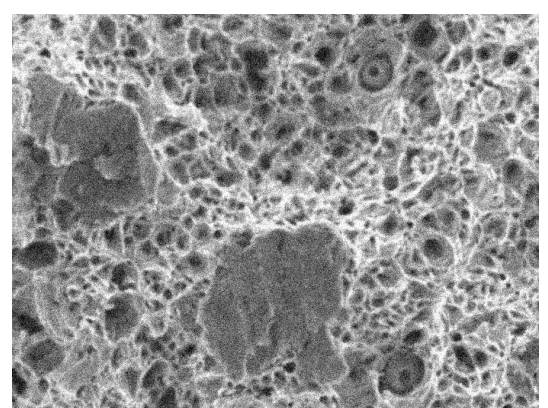

b) $\sigma^{2}=0.01$,

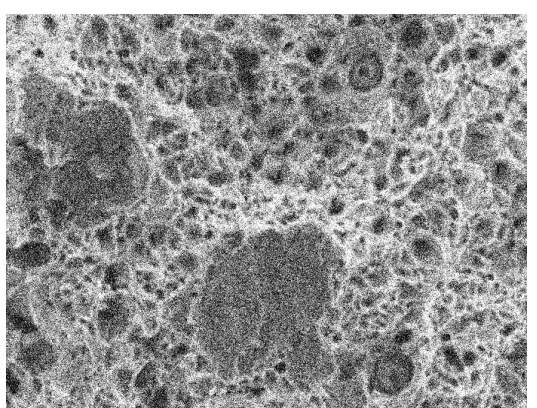

c) $\sigma^{2}=0.05$, $P S N R=20.11, f r=2.0053$ $P S N R=13.61, f r=2.0223$

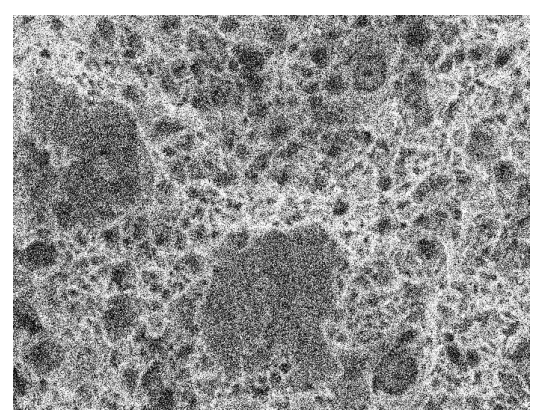

d) $\sigma^{2}=0.10, P S N R=11.31, f r=2.0250$

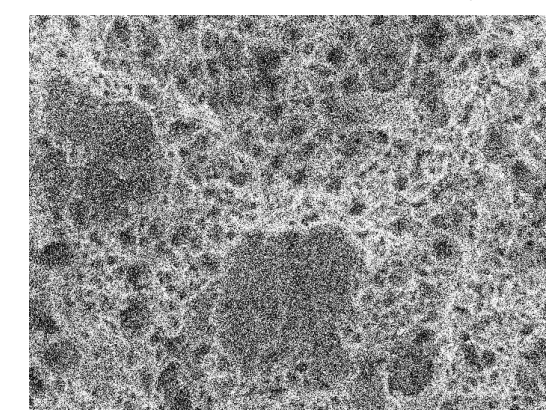

e) $\sigma^{2}=0.15, P S N R=10.18, f r=2.0259$

Fig. 4. A series of images with different levels of Gaussian noise and corresponding values of fractal dimension $f r$

We will conduct similar studies for other types of noise - pulsed and multiplicative.

In Fig. 5 images with different levels of impulse noise are shown. The parameter $d$ specifies the fraction of noise-distorted image pixels.

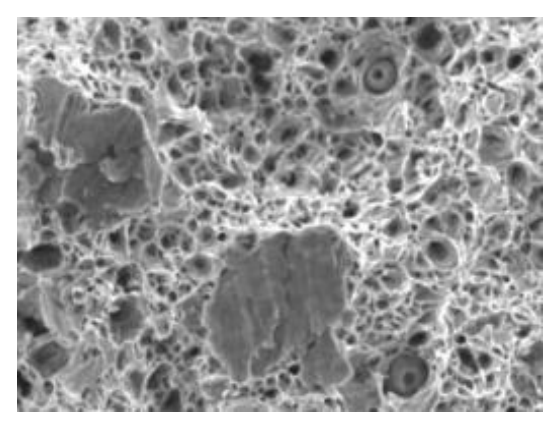

a) Input image $f r=1.9574$

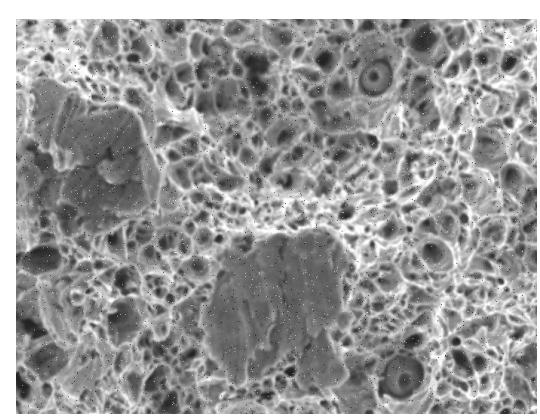

b) $d=0.01, P S N R=25.55$,

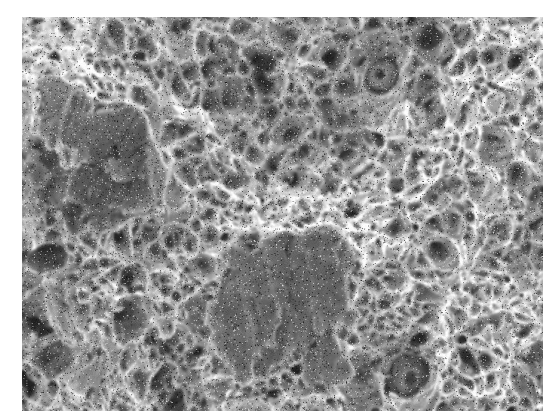

c) $d=0.05, P S N R=18.50$,

$$
f r=1.9721 \quad f r=1.9928
$$

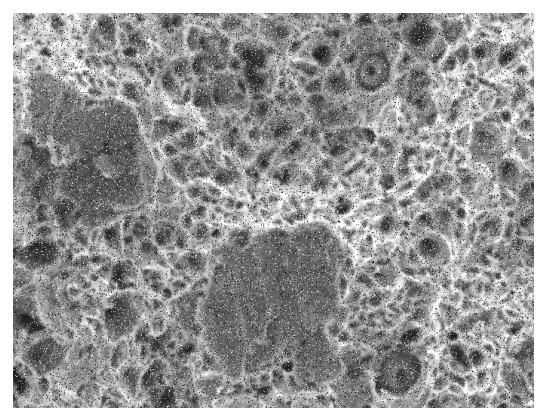

d) $d=0.10, P S N R=15.48, f r=2.0031$

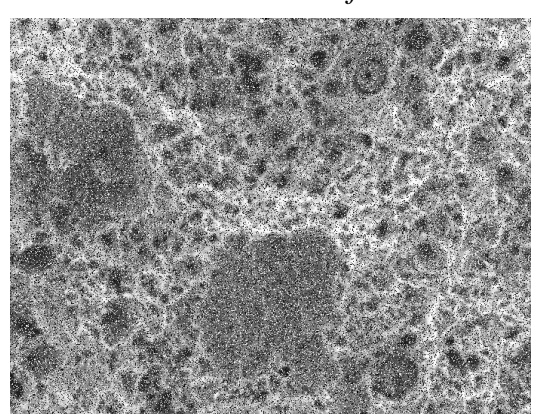

e) $d=0.25, P S N R=11.47, f r=2.0165$

Fig. 5. A series of images with different levels of pulsed noise and corresponding values of fractal dimension $f r$

The value of fractal dimensions, which are calculated for a series of images with a fraction of distorted pixels from $1 \%$ to $25 \%$, varies from 1.9721 to 2.0165 , while the fractal dimension of the input image is 1.9574 . 
In this case, the deviation of the fractal dimension from the corresponding value for the input image is $3 \%$. For some practical applications, it can be argued that the level of pulsed noise with a fraction of distorted pixels up to 0.25 , also has little effect on the value of the fractal dimension of the image.

In Fig. 6, a series of images with different levels of multiplicative noise are shown. The formation of images was carried out according to the expression:

$$
L_{\text {out }}=L_{\text {in }}+n \cdot L_{\text {in }} \text {, }
$$

where $L_{\text {in }}, L_{\text {out }}$ - the matrix of the input and the resulting image, respectively; $n$ - evenly distributed random noise with mathematical expectation $\mu=0$ and corresponding variance $\sigma^{2}$.

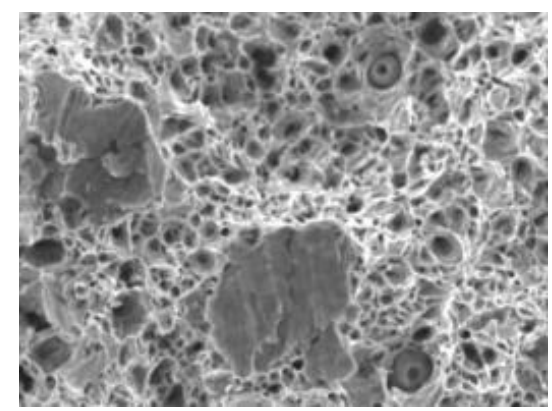

a) Input image $f r=1.9574$

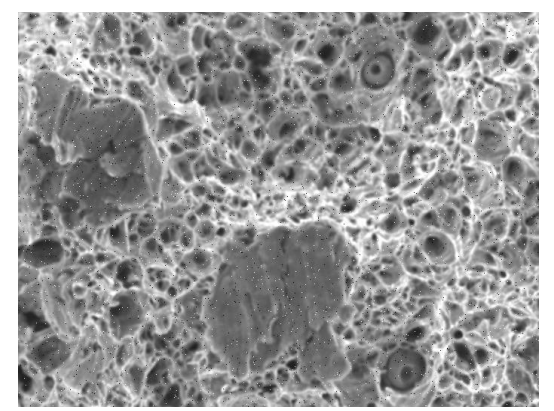

b) $\sigma^{2}=0.01, P S N R=24.75$,

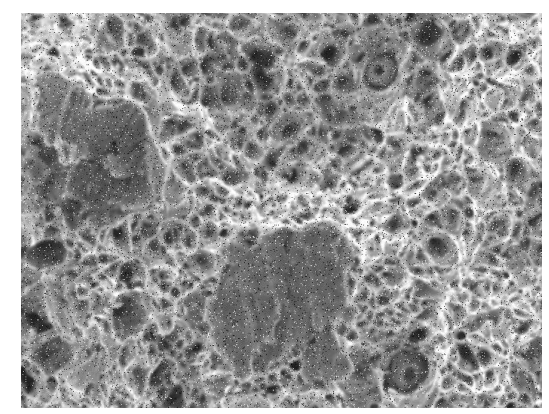

c) $\sigma^{2}=0.05, P S N R=18.01$, $f r=2.0077$

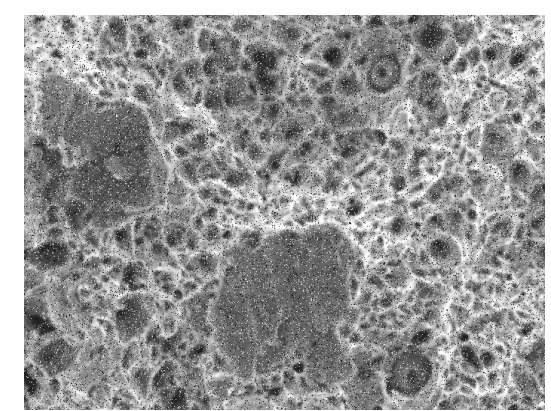

d) $\sigma^{2}=0.10, P S N R=15.19, f r=2.0175$

$$
\text { fr }=1.9803
$$

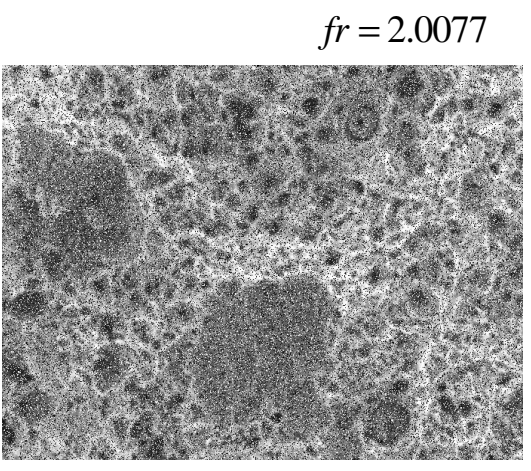

e) $\sigma^{2}=0.25, P S N R=11.66, f r=2.0233$

Fig. 6. A series of images with different levels of multiplicative noise and corresponding values of fractal dimension $f r$

Fig. 6 shows that for a series of images with a level of variance (normalized) multiplicative noise from 0.01 to 0.25 , the fatal dimension varies from 1.9803 to 2.0233 and differs from the fractal dimension of the input image by $3.3 \%$.

Fig. 7 shows a dependency graph of fractal dimensions on the type and noise level, which is expressed by the parameter PSNR.

From the above studies and the graph in Fig. 7 it can be concluded that the influence of Gaussian, pulse and multiplicative image noises on the value of the fractal dimension is insignificant. If we consider the fractal dimensions of the input and noisy images, the maximum relative error will be $3.3 \%$.

It is important to note that the above results are given for PSNR levels from 11 to $26 \mathrm{~dB}$, and the cellular and point methods were used to calculate fractal dimensions. But not all methods of calculating fractal dimensions are insensitive or low sensitive to the noise component in images. Here is an example of one of these methods, where the calculated values will vary in a slightly larger range.

Since a metallographic or factual image can be considered a stochastic structure, a variance fractal dimension can be used to estimate its fractal dimension [21], which is calculated by the expression:

$$
D_{\sigma}=D_{0}+\frac{3-D^{\prime}}{2}
$$

where $D_{0}$ - the dimension of the Euclidean space in which the fractal is embedded; $D^{\prime}$ - estimation of fractal dimension, which, in turn, is calculated by expression: 


$$
D^{\prime}=1-\frac{\log _{a} \sigma_{1}^{2}-\log _{a} \sigma_{2}^{2}}{\log _{a} m-\log _{a} n} .
$$

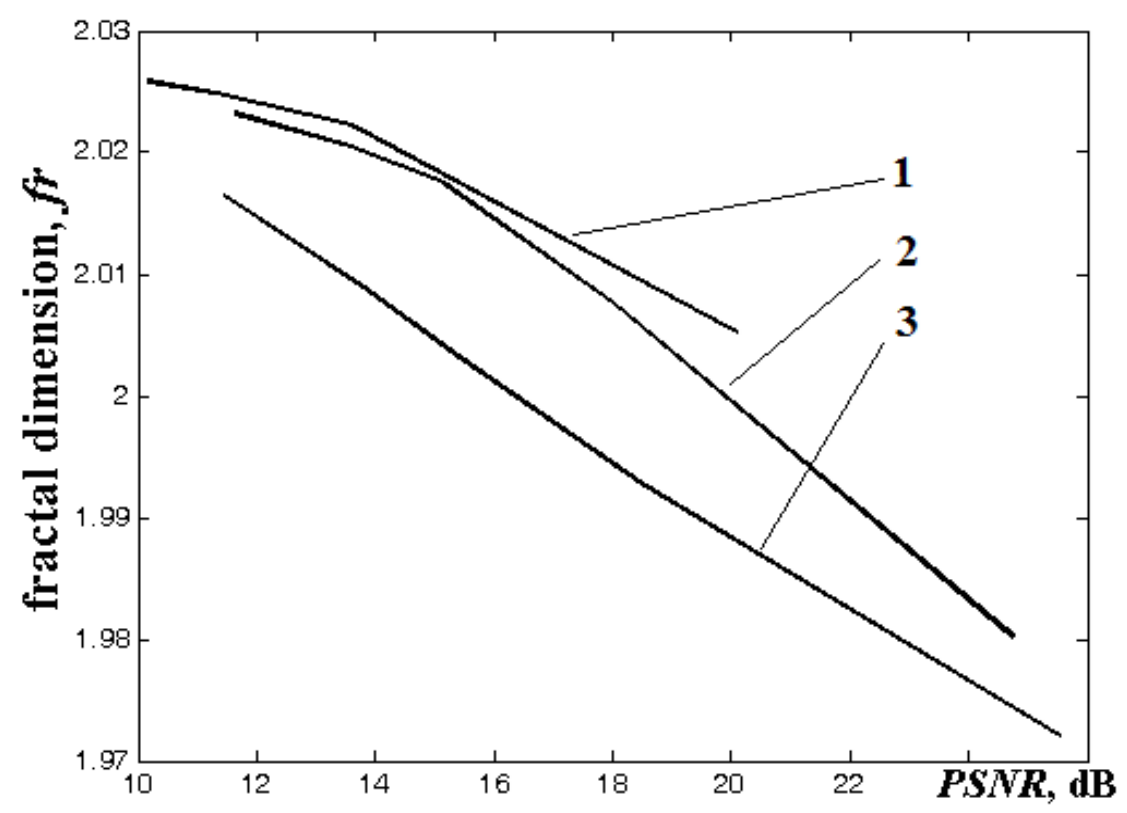

Fig. 7. Dependency graphs of fractal dimensions on type (1 - Gaussian, 2 - multiplicative, 3 - pulse noises) and noise level, which is expressed by the PSNR parameter

The choice of the basis of the logarithm $a$ is not of fundamental importance and affects only the convenience of calculations. Fig. 8 shows a series of images with superimposed pulsed noise, for which the variance fractal dimensions are calculated by expression (5).

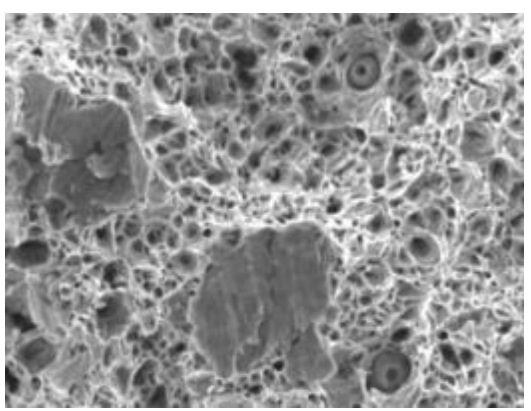

a) Input image, $f r=1.9574$

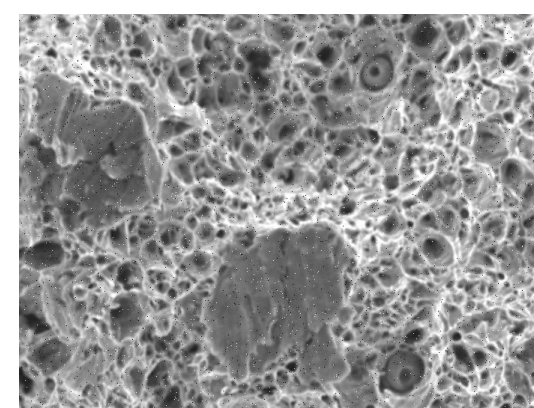

b) $d=0.01, P S N R=25.55$,

$$
\text { fr }=2.1601
$$

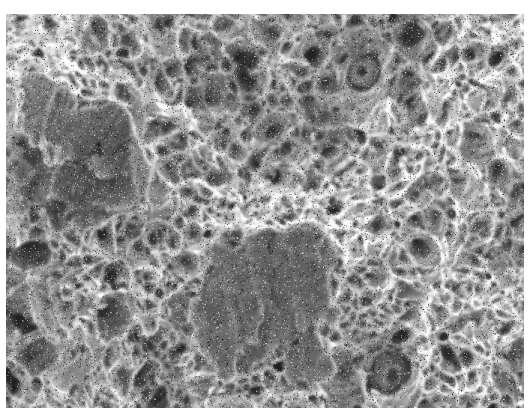

c) $d=0.05, P S N R=18.50$, $f r=2.1928$
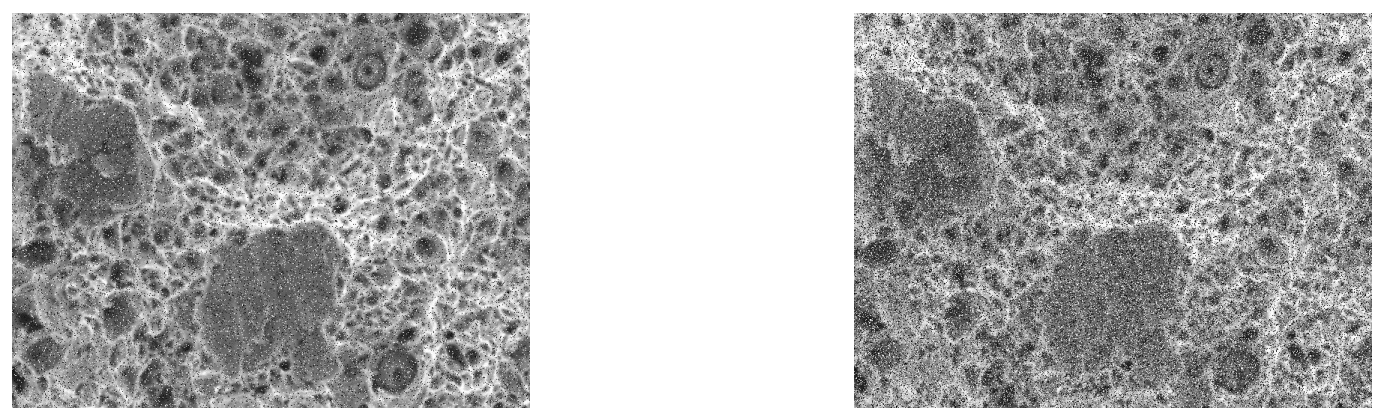

d) $d=0.10, P S N R=15.48, f r=2.2531$

e) $d=0.25, P S N R=11.47, f r=2.2716$

Fig. 8. Calculation of fractal dimensions for a series of images with different levels of impulse noise

The noise level is described by the PSNR parameter, which of this set is in the range from 25.55 to $11.47 \mathrm{~dB}$. For each of these images, values of variance fractal dimensions are calculated, the range of change of which is from 1.9574 for the input image to 2.2716 for the image with the highest noise level. The maximum 


\section{Localization of Steel Fractures Based on the Fractal Model of Their Metallographic Images}

change in the variance fractal dimension relative to the input image is more than $16 \%$. Similar calculations for the case of pulsed noise and the same set of images when calculating fractal dimensions using cellular and point methods were $3 \%$. Therefore, from the above studies it can be concluded that the methods of calculating fractal dimensions have different sensitivity to noise in the images [12]. For the case of analysis of noisy images, it is advisable to use the best convergence of cellular and point methods.

\section{Conclusions}

A promising image analysis technology is the use of fractal dimension distribution over the image field. The histogram of the field distribution of fractal dimensions significantly depends on the size of the aperture. It is established that at the size of the local aperture, which is commensurate with the size of the studied objects, the distribution modes become especially pronounced. Each of these modes indicates the presence of a texture that is characterized by a certain fractal dimension. This property is used for localization of objects in the image. In particular, when using the method of calculating the fractal dimension using the surface integral, it provides $17 \%$ less average error of localization of objects of interest compared to known analogues.

It is established that the influence of Gaussian, pulse and multiplicative image noises for PSNR levels from 11 to $26 \mathrm{~dB}$ on the value of fractal dimension depends on the method of its calculation, which should be taken into account in fractal image analysis. When calculating the fractal dimension of the image by the best convergence of cellular and point methods, the maximum relative error is $3.3 \%$.

\section{References}

[1] I. M. Zhuravel, "Avtomatychne rozpiznavannia krykhkoho ta viazkoho zlamiv stali $15 \mathrm{Kh} 1 \mathrm{MF} \mathrm{z}$ vykorystanniam fraktalnoi rozmirnosti" ["Automatic recognition of brittle and viscous fractures of 15Kh1MF steel using fractal dimension"], in Proc. of Scientific and Technical Conf. Computational Methods and Information Transformation Systems, Lviv, Ukraine, Oktober 7-8, 2010, pp. 176-178. [in Ukrainian].

[2] I. M. Zhuravel', L. M. Svirs'ka, O. Z. Student, R. A. Vorobel', and H. M. Nykyforchyn, "Automated determination of grain geometry in an exploited steam-pipeline steel", Materials Science, vol. 45, no. 3, pp. 350-357, 2009.

[3] S. A. Saltyikov, Stereometricheskaya metallografiya [Stereometric metallography]. Moscow, Russia: Metalurgiya Publ., 1976. [in Russian].

[4] V. V. Panasiuk, Y. M. Nykyforchyn, O. Z. Student, and Z. V. Slobodian, "Zastosuvannia pidkhodiv mekhaniky ruinuvannia do otsinky vodnevoi dehradatsii stalei nafto- ta paroprovodiv" ["Application of destruction mechanics approaches to the assessment of hydrogen degradation of steels of oil and steam pipelines"], in Mekhanika i fizyka ruinuvannia budivelnykh materialiv ta konstruktsii [Mechanics and physics of destruction of building materials and structures]. Lviv, Ukraine: Kameniar Publ., 2002. pp. 537-546. [in Ukrainian].

[5] M. V. Karuskevych, et al. "Strukturna poshkodzhuvanist i ruinuvannia zrazkiv-svidkiv vtomnoho poshkodzhennia" ["Structural damage and destruction of witness samples of fatigue damage"], Avyatsyonnokosmycheskaia tekhnyka i tekhnolohyia [Aerospace engineering and technology], vol. 9 (56), pp. 110-114, 2008. [in Ukrainian].

[6] R. M. Haralik, "Statisticheskiye i strukturnyiye podhody k opisaniyu tekstur" ["Statistical and structural approaches to describing textures"], Trudy instituta inzhenerov po elektrotekhnike i radioelektronike [Proceedings of the Institute of Electrical and Electronics Engineers], vol. 67, no. 5, pp. 98-120, 1979. [in Russian].

[7] V. I. Bolshakov, V. N. Volchuk, and Yu. I. Dubrov, Fraktaly v materialovedenii [Fractals in Materials Science]. Kyiv, Ukraine: PGASA Publ., 2005. [in Russian].

[8] V. M. Volchuk, "Rozrobka i doslidzhennia metodu vyznachennia yakisnykh kharakterystyk metalu na osnovi analizu fraktalnoi rozmirnosti yoho mikrostruktury" ["Development and research of a method for determining the qualitative characteristics of a metal based on the analysis of the fractal dimension of its microstructure"], Ph.D. dissertation, Prydniprovska State Academy of Civil Engineering and Architecture, Dnipropetrovsk, Ukraine, 2003. [in Ukrainian].

[9] V. I. Bolshakov, Yu. I. Dubrov, and F. V. Kryulin, V. M. Volchuk, "Sposib vyznachennia fraktalnoi rozmirnosti zobrazhen" ["The method of determining the fractal dimension of images"], UA Patent 51439A, February 02, 2002. [in Ukrainian]. 


\section{Ihor Zhuravel, Łesia Mychuda, Yurii Zhuravel}

[10] I. M. Zhuravel, "Metod binaryzatsii metalohrafichnykh zobrazhen z optymalnym porohom" "[Method of binarization of metallographic images with optimal threshold"], Shtuchnyi intelekt [Artificial Intelligence], vol. 4, pp. 142-147, 2012. [in Ukrainian].

[11] I. M. Zhuravel, and R. A. Vorobel, "Obchyslennia fraktalnykh rozmirnostei z vykorystanniam poverkhnevoho intehrala" ["Calculation of fractal dimensions using the surface integral"], Vidbir $i$ obrobka informatsii [Information extraction and processing], vol. 26 (102), pp. 95-98, 2007. [in Ukrainian].

[12] I. M. Zhuravel, "Vybir nalashtuvan pid chas obchyslennia polia fraktalnykh rozmirnostei zobrazhennia" ["Select settings when calculating the fractal dimension field of an image"], Naukovyi visnyk NLTU Ukrainy [Scientific Bulletin of UNFU], vol. 2 (28), pp. 159-163, 2018. [in Ukrainian].

[13] A. A. Rogov, "Primenenie spektra fraktalnyih razmernostey Reni kak invarianta graficheskogo izobrazheniya" ["Application of the spectrum of Renyi fractal dimensions as an invariant of a graphic image"], Vestnik Sankt-Peterburgskogo universiteta [Bulletin of St. Petersburg University], vol. 2 (10), pp. 30-43, 2008. [in Russian].

[14] L. Shapiro, and Dzh. Stokman, Kompyuternoe zrenie [Computer vision]. Moscow, Russia: Binom Publ., 2006. [in Russian].

[15] L. Vincent, and P. Soille, "Watersheds in Digital Space: An Efficient Algorithms based on Immersion Simulation”, IEEE Transactions on Pattern Analysis and Machine Intelligence, vol. 6 (13), pp.583-598, 1991.

[16] E. P. Putyatin, and S. I. Averin, Obrabotka izobrazheniy v robototehnike [Image processing in robotics]. Moscow, Russia: Mashinostroenie Publ. 1990. [in Russian].

[17] E. I. Krutasova, Nadezhnost metalla energeticheskogo oborudovaniya [Reliability of metal power equipment], Moscow, Russia: Energoizdat Publ. 1981. [in Russian].

[18] A. P. Tsapaev, and O. V. Kretinin, "Metodyi segmentatsii izobrazheniy v zadachah obnaruzheniya defektov poverhnosti" ["Image segmentation methods for surface defect detection"], Kompyuternaya optika [Computer optics], vol. 3 (36), pp. 448-452, 2012. [in Russian].

[19] E. I. Sergeeva, "Invariantnyie integralnyie harakteristiki multispektralnyih kosmicheskih izobrazheniy" ["Invariant integral characteristics of multispectral space images"], Zbirnyk naukovykh prats' Natsional'noho hirnychoho universytetu [Collection of Research Papers of the National Mining University], vol. 2, no. 35, pp. 118122, 2010. [in Russian].

[20] V. K. Ivanov, R. E. Paschenko, and A. M. Stadnik, "Ispolzovanie teorii fraktalov dlya analiza radiolokatsionnyih izobrazheniy poverhnosti Zemli" ["Using the theory of fractals for analysis of radar images of the Earth's surface"], Uspehi sovremennoy radioelektroniki [Advances in modern radioelectronics], vol. 5, pp. 17-45, 2006. [in Russian].

[21] A. A. Potapov, Noveyshie metodyi obrabotki izobrazheniy [Latest image processing techniques]. Moscow, Russia: Fizmatlit Publ., 2008. [in Russian]. 